\title{
BODY BUILD AND THE LEVEL OF DEVELOPMENT OF MUSCLE STRENGTH AMONG MALE JIU-JITSU COMPETITORS AND STRENGTH-TRAINED ADULTS
}

doi: 10.1515/humo-2015-0002

\author{
JADWIGA PIETRASZEWSKA*, ANNA BURDUKIEWICZ, ALEKSANDRA STACHOŃ, \\ JUSTYNA ANDRZEJEWSKA, TADEUSZ STEFANIAK, KAZIMIERZ WITKOWSKI \\ University School of Physical Education, Wrocław, Poland
}

\begin{abstract}
Purpose. The aim of the present study was to assess the morpho-functional characteristics of male jiu-jitsu practitioners against a sample of strength-trained university students. Methods. The all-male research sample included 49 jiu-jitsu competitors and 30 university students actively involved in strength training. Measures of body mass and height, lower extremity length, sitting height, arm span, trunk width, skeletal breadths, circumferences and skinfold thicknesses of the trunk and extremities were collected. Body tissue composition was assessed using bioelectrical impedance analysis. Somatotype was classified according to the anthropometric method of Heath and Carter. Participants also performed three motor tests composed of the standing long jump, flexed arm hang, and sit-ups and two dynamometer tests measuring handgrip and back muscle strength. Differences between the measured characteristics in both samples were analyzed using Student's $t$ test. Pearson's correlation coefficient was used to the determine the relationships between the morphological characteristics and the results of the motor tests. Results. The jiu-jitsu sample was slightly smaller than the strength-training students. In contrast, body mass was almost identical in both groups. The remaining length, height, and skinfold characteristics also did not differ significantly between the groups. Only hip breadth was significantly larger in the jiu-jitsu sample. No between-group differences were noted in the levels of endomorphy, mesomorphy, and ectomorphy. The composite somatotype of the jiu-jitsu athletes (2.1-5.8-2.0) was very similar to that of the strength-trained students (2.1-5.9-2.4). Statistically significant differences were observed in the tests assessing muscle strength. Handgrip and back muscle strength was greater in the strength-training students, whereas the jiu-jitsu athletes performed better in all three motor tests. Conclusions. The minor morphological differences between the jiu-jitsu and strength-training groups may be due to the different sporting level of the participants. Whereas the intense weight training regime of the strength-training students allowed them to achieve higher results in the dynamometer tests, the more multidimensional aspect of jiu-jitsu training was reflected in achieving better results in the motor tests.
\end{abstract}

Key words: jiu-jitsu, body build, motor tests

\section{Introduction}

The body build profile of athletes is the result of both athlete selection criteria and training loads. Each sport involves various form of training, the aim of which is to generally improve certain fitness measures and overall physical performance, whereas the aim of more targeted training programs specific to each sport is to induce specific changes in body morphology as well as various functional characteristics. It is the combination of optimal training and the most suitable somatic predispositions that allow an athlete to attain the best results in today's ever more specialized and technical world of sports. One of the most basic elements of any sports training program is developing strength [1]. Muscle strength plays a key role in determining sporting success not only in typical strength sports such as weightlifting, powerlifting, and bodybuilding [2], but also in martial arts, track and field, and team sports.

\footnotetext{
* Corresponding author.
}

In recent years there has been an upsurge of interest in jiu-jitsu among the martial arts community with its combination of elements from karate and judo [3]. The mixed style of jiu-jitsu promotes a wide variety of techniques and tactics. The full range of jiu-jitsu techniques covers grips, throws, holds, joint locks, chokes, hits, kicks, and inflicting blows on sensitive parts of the body in various ways. One of the defining concepts behind jiu-jitsu is that a theoretically weaker athlete should be able to successfully subdue a stronger, larger opponent. Hence, jiu-jitsu favors individuals with high levels of flexibility, agility, speed, coordination, and balance [4] and not pure physical strength. Nonetheless, strength training is important for jiu-jitsu practitioners as it aids in certain moves such as throwing or choking. For these moves and others, upper body strength plays a large role as jiu-jitsu is a close and full contact sport that does not provide the space needed for more dynamic moves [5]. Alongside the importance of upper body strength is also muscular endurance, used to hold and maintain the most advantageous position when grappling against an opponent. Alongside the above, handgrip strength is also important as it is very effective in holding down an opponent by their kimono. 
Research on the somatotypes of martial arts athletes in different weight classes is quite comprehensive. However, relatively little work has been performed on jiu-jitsu practitioners. Of those few available studies, most have focused on reporting mean body mass and height, body tissue composition, or types of body build. There remains a paucity of information when considering detailed anthropometric data and comparing morphological characteristics with strength measures. Particular interesting seems to be comparing the motor performance (strength-related) of jiu-jitsu practitioners against athletes specialized in strength training.

The aim of the present study was to therefore compare the morphology, body tissue composition, and strength capabilities of jiu-jitsu against a population engaged in strength-training. This included examining the relationship between the strength levels and anthropometric characteristics between both groups.

\section{Material and methods}

The all-male research sample included 49 professional jiu-jitsu practitioners (mean age 23.40 years) and 30 university students actively involved in strength training (mean age 22.32 years). All participants weighed between $70-90 \mathrm{~kg}$. The jiu-jitsu group had been involved in the sport between 4 to 12 years and trained on average four times per week for 2 hours. The comparative group had been involved in an adaptive strength training program for 3 months whose aim was to improve muscular endurance [6]. This group trained three times per week (every other day) by lifting weights. Each training session consisted of two exercises targeting each major muscle group, with ninety seconds of rest provided between the exercises. The first training session began by performing one set of 19 repetitions for each exercise at a suitable weight. The number of repetitions was then increased by one each subsequent training session until reaching 24 repetitions. Afterwards the number of sets was increased to two, with the participants again completing 19 repetitions per set with the number of repetitions increased by one each subsequent exercise session until again reaching 24 . Finally, participants completed three sets (from 19 to 24 repetitions). The next step was to return to completing two sets of 19 repetitions in each exercise but this time increasing the weight by $5 \%$ in each subsequent session. Upon completing this introductory phase, training was varied for each exercise by increasing, in order, the number of repetitions (from 19 to 24 ), then the number of sets (from two to three), and then the weight (by 5\%).

Data were collected through anthropometric measurement and administering fitness/strength tests. An anthropometer (GPM, Switzerland) was used to measure body height, lower extremity length, sitting height, and arm span. Measures of the trunk and extremities were performed using a spreading caliper of the same manu- facturer. These included chest diameter, chest depth, biacromial diameter, biiliocristal diameter, and deltoid muscle diameter. Measures of bone breadths included elbow breadth and knee breadth. In addition, circumferences of the neck, shoulder, chest, waist, hips, arm (contracted and relaxed), and the maximal circumferences of the forearm, thigh, and calf were taken. A body fat caliper (Harpenden, UK) was used to obtain skinfold thicknesses at the subscapular, triceps, suprailiac, abdominal, and calf sites. Body mass was assessed using an electronic scale.

The relationship between height and mass was assessed by body mass index. Somatotype was classified according to Sheldon's method of somatotopy as modified by Heath and Carter to determine the levels of endomorphy, mesomorphy, and ectomorphy. Body tissue composition was determined using a BIA 101 bioelectrical impedance analyzer (Akern, Italy) with the packaged Bodygram software. Variables considered for analysis included body fat mass, lean body mass, and water content. Muscle strength was assessed by dynamometer testing; this included measuring (a) handgrip strength using an adjustable hand dynamometer (Takei, Japan) with a measuring range of 0-100 kgf (kilogram-force) and $0.5 \mathrm{kgf}$ accuracy and (b) back muscle strength using a back dynamometer of the same manufacturer with a measuring range of $0-250 \mathrm{kgf}$ and $0.5 \mathrm{kgf}$ accuracy. Physical fitness was assessed by three motor tests consisting of the standing long jump (distance jumped), flexed arm hang (time spent hanging), and sit-ups (number completed within a set time).

Basic statistical methods were used to analyze the obtained results. Means and standard deviations were calculated. The statistical distribution of the variables were assessed with the Kolmogorov-Smirnov test, finding it did not differ significantly from a normal distribution. On this basis all subsequent statistical methods assumed a normal distribution. Inter-group differences were determined by Student's $t$ test, whereas the relationships between the muscle strength variables and morphological characteristics were examined using Pearson's product-moment correlation coefficient.

The study was financed by the Polish Ministry of Science and Higher Education in a project titled Muscle strength development among martial arts and fighting sports athletes differentiated by morphological structure (No. NRSA1 001551). The study design was approved by the Ethics Committee of the University of Physical Education in Wroclaw, Poland and all participants provided their written informed consent.

\section{Results}

Body mass was almost identical in both groups (Table 1). However, the jiu-jitsu sample was slightly smaller than the strength-training students, whereas those strength lifting had significantly smaller biiliocristal 
diameter and chest depth values. On the other hand, the jiu-jitsu practitioners were characterized by a smaller hip circumference (Table 2). No significant differences were found between both groups among the skinfold thickness and length/height characteristics. For body composition a significantly higher percentage of lean body mass and water content was presented by the jiujitsu practitioners (Table 3). Conversely, the strengthtraining group had higher fat content, measured both in kilograms and as a percentage. No between-group differences were noted in the levels of endomorphy, mesomorphy, and ectomorphy. The somatotype of the jiu-jitsu athletes (2.1-5.8-2.0) was very similar to that of the strength-trained students (2.1-5.9-2.4). A number of significant differences were observed in the tests assessing muscle strength (Table 4). Although the differences for handgrip strength were not statistically significant, the strength-training group presented slightly higher results. Significantly higher values were found in this group for back muscle strength. In turn, the jiu-jitsu ath- letes performed better in all three motor tests (standing long jump, flexed arm hang, and sit-ups). However, a statistically significant difference was recorded only in the standing long jump test.

In both groups, a significant positive correlation was observed between the majority of the somatic characteristics and the dynamometer tests (handgrip and back strength). In the case of the other three motor tests, any correlations with the morphological characteristics were quite low, with the majority non-significant (Table 5, 6). However, the strength-training group featured a slightly more pronounced relationship between a lower time (poorer result) in the flexed arm hang test and an increase in the values of the analyzed somatic characteristics. A statistically significant negative correlation was found between flexed arm hang time and the circumferences of the thigh and calf, whereas a positive correlation was found between flexed arm hang test and ectomorphy. No statistically significant dependencies were observed between any of the somatic characteris-

Table 1. Statistical characteristics of the length/height measurements and body mass

\begin{tabular}{|c|c|c|c|c|c|}
\hline \multirow{2}{*}{ Variable } & \multicolumn{2}{|c|}{ Jiu-jitsu group } & \multicolumn{2}{|c|}{ Strength-training group } & \multirow{2}{*}{$p$} \\
\hline & Mean & $S D$ & Mean & $S D$ & \\
\hline Body mass (kg) & 77.3 & 6.47 & 78.3 & 6.83 & 0.620 \\
\hline Body height (cm) & 177.6 & 6.40 & 180.4 & 4.44 & 0.064 \\
\hline Lower extremity length $(\mathrm{cm})$ & 95.5 & 3.64 & 94.4 & 4.23 & 0.288 \\
\hline Sitting height $(\mathrm{cm})$ & 93.0 & 3.68 & 93.8 & 2.87 & 0.372 \\
\hline Arm span $(\mathrm{cm})$ & 180.9 & 7.37 & 184.2 & 7.21 & 0.076 \\
\hline Biacromial diameter $(\mathrm{cm})$ & 42.3 & 1.90 & 41.6 & 2.39 & 0.172 \\
\hline Deltoid muscle diameter $(\mathrm{cm})$ & 47.0 & 2.25 & 47.3 & 1.90 & 0.566 \\
\hline Chest diameter (cm) & 29.6 & 2.35 & 28.8 & 2.18 & 0.171 \\
\hline Chest depth $(\mathrm{cm})$ & 20.8 & 1.74 & 19.9 & 1.58 & 0.035 \\
\hline Biiliocristal diameter $(\mathrm{cm})$ & 29.0 & 1.76 & 27.8 & 1.99 & 0.013 \\
\hline Elbow breadth (cm) & 7.1 & 0.32 & 7.1 & 0.66 & 0.889 \\
\hline Knee breadth $(\mathrm{cm})$ & 10.1 & 0.53 & 10.2 & 1.26 & 0.651 \\
\hline
\end{tabular}

Values in bold denote statistical significance at $p<0.05$

Table 2. Statistical characteristics of the circumference measurements

\begin{tabular}{|c|c|c|c|c|c|}
\hline \multirow{2}{*}{ Variable } & \multicolumn{2}{|c|}{ Jiu-jitsu group } & \multicolumn{2}{|c|}{ Strength-traininggroup } & \multirow{2}{*}{$p$} \\
\hline & Mean & $S D$ & Mean & $S D$ & \\
\hline Neck circumference $(\mathrm{cm})$ & 39.5 & 1.77 & 38.9 & 1.68 & 0.205 \\
\hline Shoulder circumference $(\mathrm{cm})$ & 118.3 & 4.87 & 118.7 & 4.72 & 0.716 \\
\hline Chest circumference $(\mathrm{cm})$ & 89.0 & 4.43 & 90.4 & 7.88 & 0.326 \\
\hline Waist circumference $(\mathrm{cm})$ & 80.6 & 5.20 & 81.3 & 5.81 & 0.606 \\
\hline Arm circumference - relaxed $(\mathrm{cm})$ & 32.7 & 2.11 & 33.2 & 2.67 & 0.445 \\
\hline Arm circumference - contracted $(\mathrm{cm})$ & 35.9 & 2.34 & 36.2 & 2.67 & 0.557 \\
\hline Maximal forearm circumference $(\mathrm{cm})$ & 28.1 & 1.30 & 28.6 & 1.49 & 0.128 \\
\hline Hip circumference $(\mathrm{cm})$ & 96.4 & 4.67 & 99.1 & 4.62 & 0.026 \\
\hline Maximal thigh circumference $(\mathrm{cm})$ & 57.9 & 3.36 & 57.3 & 3.58 & 0.452 \\
\hline Maximal calf circumference $(\mathrm{cm})$ & 37.5 & 2.09 & 38.0 & 2.68 & 0.367 \\
\hline
\end{tabular}

Values in bold denote statistical significance at $p<0.05$ 
Table 3. Statistical characteristics of somatotype, skinfold thickness, and body tissue composition

\begin{tabular}{|c|c|c|c|c|c|}
\hline \multirow{2}{*}{ Variable } & \multicolumn{2}{|c|}{ Jiu-jitsu group } & \multicolumn{2}{|c|}{ Strength-training group } & \multirow{2}{*}{$p$} \\
\hline & Mean & $S D$ & Mean & $S D$ & \\
\hline Body mass index & 24.5 & 1.98 & 24.1 & 1.96 & 0.436 \\
\hline Endomorphy & 2.1 & 0.62 & 2.1 & 0.73 & 0.811 \\
\hline Mesomorphy & 5.8 & 0.95 & 5.9 & 1.60 & 0.884 \\
\hline Ectomorphy & 2.0 & 0.84 & 2.4 & 0.77 & 0.112 \\
\hline Subscapular skinfold thickness (mm) & 10.2 & 2.54 & 10.0 & 2.48 & 0.771 \\
\hline Triceps skinfold thickness (mm) & 4.9 & 1.91 & 4.8 & 1.59 & 0.787 \\
\hline Suprailiac skinfold thickness (mm) & 7.8 & 2.83 & 8.0 & 3.16 & 0.782 \\
\hline Abdominal skinfold thickness (mm) & 9.4 & 3.66 & 10.2 & 4.20 & 0.390 \\
\hline Calf skinfold thickness (mm) & 4.5 & 1.76 & 4.7 & 1.61 & 0.660 \\
\hline Fat mass (kg) & 12.3 & 3.90 & 14.1 & 3.52 & 0.058 \\
\hline Fat-free mass (kg) & 65.0 & 6.43 & 64.3 & 6.57 & 0.646 \\
\hline Total body water (kg) & 47.6 & 4.64 & 47.1 & 4.81 & 0.622 \\
\hline Fat mass $(\%)$ & 15.7 & 4.00 & 17.9 & 3.81 & 0.027 \\
\hline Fat-free mass (\%) & 84.3 & 4.00 & 82.1 & 3.81 & 0.027 \\
\hline Total body water (\%) & 61.8 & 3.02 & 60.1 & 2.79 & 0.024 \\
\hline
\end{tabular}

Values in bold denote statistical significance at $p<0.05$

Table 4. Statistical characteristics of the motor test results

\begin{tabular}{lccccc}
\hline \multirow{2}{*}{ Variable } & \multicolumn{2}{c}{ Jiu-jitsu group } & \multicolumn{2}{c}{ Strength-training group } & \multirow{2}{*}{$p$} \\
\cline { 2 - 4 } & Mean & SD & Mean & SD & \\
\hline Right handgrip strength (kgf) & 47.8 & 8.31 & 51.4 & 10.07 & 0.111 \\
Left handgrip strength (kgf) & 46.2 & 7.59 & 48.6 & 10.31 & 0.252 \\
Back strength (kgf) & 123.9 & 21.73 & 140.7 & 18.82 & $\mathbf{0 . 0 0 2}$ \\
Flexed arm hang (s) & 40.2 & 10.99 & 34.9 & 13.18 & 0.076 \\
Standing long jump (cm) & 233.5 & 22.03 & 217.7 & 19.58 & $\mathbf{0 . 0 0 4}$ \\
Sit-ups $(n)$ & 34.5 & 4.85 & 33.9 & 3.87 & 0.566 \\
\hline
\end{tabular}

Values in bold denote statistical significance at $p<0.05$

tics and the results of the flexed arm hang test in the jiu-jitsu group.

For the standing long jump a positive correlation was established between this motor test and a number of the length/height characteristics in both groups. In the strength-training group, the strongest positive correlation was observed between standing long jump performance and lower extremity length. For the jiu-jitsu group, the largest positive correlations were with body height, knee breadth, and circumference of the waist. A clear result was found between poorer long jump distance and increased skinfold thickness among the students involved with strength training. No such dependency was found in the jiu-jitsu group.

The correlation coefficients between the sit-ups test and the morphological characteristics in both groups had low values. Only in the strength-training group could a dependency be observed between an improvement in the number of sit-ups with a stronger and better developed upper body.

\section{Discussion}

The techniques and training methods used in combat sports are vastly diverse. As a result, there are no specific morphological criteria for those involved in these sports. However, research conducted on judo, jiu-jitsu, and karate practitioners showed only a slight variation in their morphological structure [3, 7]. Many authors have indicated that choosing the most optimal fighting technique in a combat sport may be better determined by an athlete's somatic predisposition [8]. In practice, Lech et al. found that taller and thinner individuals were more likely to use leg techniques, while those larger and shorter had a larger preponderance of using hand techniques [9]. In the same study, differences were also found in the effectiveness of countermaneuvers depending on body height. It is nonetheless apparent that the specialized forms of training inherent in combat sports cause practitioners to develop in ways most practical for combat and, as a re- 
J. Pietraszewska et al., Morpho-functional characteristics of jiu-jitsu practitioners

Table 5. Pearson's correlations between the results of the motor tests and the morphological characteristics and body tissue components in the jiu-jitsu group

\begin{tabular}{|c|c|c|c|c|c|c|}
\hline Variable & $\begin{array}{c}\text { Right } \\
\text { handgrip } \\
\text { strength }\end{array}$ & $\begin{array}{c}\text { Left } \\
\text { handgrip } \\
\text { strength }\end{array}$ & $\begin{array}{c}\text { Back } \\
\text { strength }\end{array}$ & $\begin{array}{c}\text { Flexed } \\
\text { arm hang }\end{array}$ & $\begin{array}{l}\text { Standing } \\
\text { long jump }\end{array}$ & Sit-ups \\
\hline Body mass & 0.36 & 0.27 & 0.35 & -0.08 & 0.26 & 0.06 \\
\hline Body height & 0.26 & 0.26 & 0.18 & -0.11 & 0.31 & 0.10 \\
\hline Lower extremity length & 0.16 & 0.19 & 0.08 & -0.10 & 0.20 & 0.05 \\
\hline Sitting height & 0.22 & 0.14 & 0.11 & -0.09 & 0.24 & 0.02 \\
\hline Arm span & 0.29 & 0.29 & 0.34 & -0.17 & 0.30 & 0.01 \\
\hline Biacromial diameter & 0.34 & 0.30 & 0.35 & -0.05 & 0.21 & -0.01 \\
\hline Deltoid muscle diameter & 0.29 & 0.21 & 0.27 & -0.02 & 0.25 & 0.05 \\
\hline Chest diameter & 0.36 & 0.23 & 0.19 & -0.04 & 0.22 & 0.03 \\
\hline Chest depth & 0.02 & 0.04 & 0.06 & 0.02 & 0.11 & 0.11 \\
\hline Biiliocristal diameter & 0.13 & 0.06 & 0.30 & -0.16 & 0.21 & 0.04 \\
\hline Elbow breadth & 0.25 & 0.22 & 0.14 & -0.07 & 0.12 & 0.10 \\
\hline Knee breadth & 0.32 & 0.15 & 0.17 & 0.03 & 0.34 & 0.19 \\
\hline Neck circumference & -0.01 & -0.05 & 0.07 & -0.17 & -0.09 & -0.07 \\
\hline Shoulder circumference & 0.44 & 0.35 & 0.40 & -0.08 & 0.24 & 0.00 \\
\hline Chest circumference & 0.29 & 0.17 & 0.30 & -0.02 & 0.24 & 0.16 \\
\hline Waist circumference & 0.28 & 0.19 & 0.32 & 0.06 & 0.32 & 0.13 \\
\hline Arm circumference - relaxed & 0.21 & 0.16 & 0.36 & -0.13 & -0.01 & -0.11 \\
\hline Arm circumference - contracted & 0.16 & 0.15 & 0.35 & -0.12 & 0.04 & -0.14 \\
\hline Maximal forearm circumference & 0.40 & 0.32 & 0.45 & -0.05 & 0.12 & -0.05 \\
\hline Hip circumference & 0.32 & 0.25 & 0.27 & 0.00 & 0.18 & 0.10 \\
\hline Maximal thigh circumference & 0.31 & 0.19 & 0.34 & 0.03 & 0.16 & 0.14 \\
\hline Maximal calf circumference & 0.37 & 0.27 & 0.25 & 0.01 & 0.20 & 0.07 \\
\hline Subscapular skinfold thickness & -0.02 & -0.10 & 0.09 & -0.09 & -0.09 & -0.04 \\
\hline Triceps skinfold thickness & -0.06 & -0.04 & -0.06 & 0.09 & 0.12 & 0.07 \\
\hline Suprailiac skinfold thickness & 0.10 & 0.08 & 0.00 & 0.00 & 0.10 & -0.04 \\
\hline Abdominal skinfold thickness & 0.13 & 0.13 & 0.02 & 0.06 & 0.28 & 0.10 \\
\hline Calf skinfold thickness & 0.00 & -0.03 & -0.20 & -0.01 & 0.13 & 0.07 \\
\hline Fat-free mass & 0.36 & 0.29 & 0.30 & 0.02 & 0.27 & 0.14 \\
\hline Total body water & 0.36 & 0.29 & 0.30 & 0.03 & 0.29 & 0.13 \\
\hline Fat mass & 0.18 & 0.11 & 0.26 & -0.20 & 0.11 & -0.09 \\
\hline Endomorphy & -0.02 & -0.06 & 0.01 & 0.00 & 0.00 & -0.03 \\
\hline Mesomorphy & 0.28 & 0.17 & 0.24 & 0.23 & 0.16 & 0.20 \\
\hline Ectomorphy & -0.13 & -0.03 & -0.21 & 0.00 & 0.06 & 0.05 \\
\hline
\end{tabular}

sult, be distinguished from athletes involving in other disciplines.

The present study found minor differences among some of the analyzed morphological and functional characteristics between jiu-jitsu practitioners and individuals engaged in strength training. Based on the literature on the subject, the mass-height values of the jiu-jitsu group were typical for practitioners of this sport. Andreato et al. studied Brazilian jiu-jitsu practitioners from three ranks finding mean body mass to be $75.4 \mathrm{~kg}$ and mean body height $174.9 \mathrm{~cm}$ [10]. Similar values were reported by Costa et al., with body mass $75.2 \pm 11.2 \mathrm{~kg}$, body height $173.0 \pm 8.2 \mathrm{~cm}$, and BMI $25.1 \pm 3.8 \mathrm{~kg} / \mathrm{m}^{2}$ [4]. These results show this to be the most common massheight relationship in jiu-jitsu practitioners and therefore can be used as benchmark for athletes as the mass and height range needed to better take advantage of the full range of techniques and counter-maneuvers in this sport.

Analysis of skinfold thickness indicated a similar distribution of fat in both groups. The largest values were recorded at the subscapular and abdominal sites, although the jiu-jitsu group had significantly lower body fat percentage. However, body fat content was larger in both groups when compared with values reported by other authors [8, 11], with this possibly explained by the fact that the participants examined in this study were less experienced than in the above-cited studies. Due to the nature of combat, low body fat content in different parts of the body is known to help in fighting at a faster speed as well as reacting more quickly to an opponent's moves [11]. 
Table 6. Pearson's correlations between the results of the motor tests and the morphological characteristics and body tissue components in the strength-training group

\begin{tabular}{|c|c|c|c|c|c|c|}
\hline Variable & $\begin{array}{c}\text { Right } \\
\text { handgrip } \\
\text { strength }\end{array}$ & $\begin{array}{c}\text { Left } \\
\text { handgrip } \\
\text { strength }\end{array}$ & $\begin{array}{c}\text { Back } \\
\text { strength }\end{array}$ & $\begin{array}{c}\text { Flexed } \\
\text { arm hang }\end{array}$ & $\begin{array}{l}\text { Standing } \\
\text { long jump }\end{array}$ & Sit-ups \\
\hline Body mass & 0.51 & 0.67 & 0.40 & -0.30 & 0.06 & 0.21 \\
\hline Body height & 0.44 & 0.45 & 0.25 & 0.13 & 0.31 & 0.07 \\
\hline Lower extremity length & 0.34 & 0.35 & 0.19 & -0.06 & 0.49 & 0.17 \\
\hline Sitting height & 0.41 & 0.52 & 0.38 & 0.29 & 0.04 & 0.09 \\
\hline Arm span & 0.16 & 0.23 & 0.10 & -0.05 & 0.39 & 0.09 \\
\hline Biacromial diameter & 0.23 & 0.38 & 0.32 & 0.06 & 0.18 & 0.40 \\
\hline Deltoid muscle diameter & 0.24 & 0.41 & 0.43 & 0.12 & 0.05 & 0.19 \\
\hline Chest diameter & 0.43 & 0.58 & 0.33 & 0.04 & -0.04 & 0.03 \\
\hline Chest depth & 0.32 & 0.38 & 0.29 & -0.31 & -0.13 & 0.14 \\
\hline Biiliocristal diameter & 0.01 & 0.18 & -0.02 & 0.21 & 0.14 & -0.03 \\
\hline Elbow breadth & 0.01 & 0.05 & 0.16 & -0.22 & 0.04 & 0.18 \\
\hline Knee breadth & -0.03 & -0.03 & 0.04 & -0.20 & 0.09 & 0.27 \\
\hline Neck circumference & 0.08 & 0.09 & 0.44 & 0.01 & 0.08 & -0.05 \\
\hline Shoulder circumference & 0.35 & 0.62 & 0.25 & -0.05 & 0.03 & 0.22 \\
\hline Chest circumference & 0.12 & 0.38 & 0.09 & -0.29 & 0.01 & 0.37 \\
\hline Waist circumference & 0.20 & 0.25 & 0.23 & -0.11 & -0.26 & -0.28 \\
\hline Arm circumference - relaxed & 0.60 & 0.58 & 0.37 & -0.28 & -0.05 & 0.16 \\
\hline Arm circumference - contracted & 0.49 & 0.55 & 0.39 & -0.16 & -0.09 & 0.13 \\
\hline Maximal forearm circumference & 0.60 & 0.69 & 0.40 & -0.20 & 0.05 & 0.13 \\
\hline Hip circumference & 0.29 & 0.33 & 0.12 & -0.19 & -0.31 & -0.17 \\
\hline Maximal thigh circumference & 0.26 & 0.33 & 0.13 & -0.49 & 0.01 & 0.20 \\
\hline Maximal calf circumference & 0.40 & 0.42 & 0.12 & -0.44 & 0.08 & 0.16 \\
\hline Subscapular skinfold thickness & 0.14 & 0.10 & -0.02 & -0.30 & -0.17 & -0.07 \\
\hline Triceps skinfold thickness & -0.19 & -0.26 & -0.55 & -0.19 & -0.41 & -0.31 \\
\hline Suprailiac skinfold thickness & 0.04 & 0.00 & -0.23 & -0.27 & -0.42 & -0.19 \\
\hline Abdominal skinfold thickness & 0.00 & 0.15 & -0.35 & -0.23 & -0.40 & 0.01 \\
\hline Calf skinfold thickness & 0.20 & 0.22 & -0.03 & -0.20 & -0.36 & -0.17 \\
\hline Fat-free mass & 0.47 & 0.61 & 0.28 & -0.19 & 0.20 & 0.28 \\
\hline Total body water & 0.47 & 0.61 & 0.28 & -0.19 & 0.20 & 0.27 \\
\hline Fat mass & 0.23 & 0.30 & 0.33 & -0.27 & -0.22 & -0.06 \\
\hline Endomorphy & -0.01 & -0.06 & -0.26 & -0.29 & -0.40 & -0.20 \\
\hline Mesomorphy & 0.10 & 0.13 & 0.16 & -0.36 & -0.04 & 0.26 \\
\hline Ectomorphy & -0.18 & -0.32 & -0.22 & 0.46 & 0.23 & -0.15 \\
\hline
\end{tabular}

In terms of somatotype (endomorphy, mesomorphy, and ectomorphy), the body type of the participants in this study was found to be in line with those found in strength-training and combat sports populations [12-15]. The dominance of mesomorphy in both groups point to the strong development of muscle mass and muscle hypertrophy as well as increased skeletal size. The above characteristics could also be observed in the high values recorded in the handgrip strength test. Here, handgrip strength (right and left hand) values were larger than those recorded by Andreato et al. on Brazilian jiu-jitsu practitioners in the same weight class $(70-90 \mathrm{~kg})$, who obtained $43.7 \pm 4.8 \mathrm{kgf}$ for the right hand and $40.1 \pm$ $3.8 \mathrm{kgf}$ for the left hand [5]. This was especially visible in the high values attained by the strength-training participants in the present study and can be assumed to be the result of their involvement in such an intense weight training program $[2,16]$. Of interest is the fact that Diaz et al. did not find larger absolute handgrip strength values for a population of judokas when compared with an untrained sample [17]. However, the judokas in that study were found to be more resistant to fatigue during this test, with this difference in strength endurance associated with the need to maintain a strong grip on an opponent's kimono during combat.

The standing long jump is used to assess lower extremity explosive strength. The ascendancy of the jiujitsu group over the strength-training group may stem from their multifaceted training regime that develops not just strength but also flexibility, agility, speed, coordination, and balance. In addition, the muscular work involved in combat has both a static and dynamic charac- 
ter [18]. The distance jumped in the standing long jump by the jiu-jitsu participants $(233.5 \mathrm{~m})$ in the present study was quite similar to that presented by Sertic et al. on a population of judokas, achieving a mean distance of $238.16 \mathrm{~cm}$ [18].

The results of the flexed arm hang and sit-ups test in both groups demonstrate the participants' high level of muscular endurance. This result confirms that abdominal muscle and upper body strength are critical in martial arts, and that martial arts training is justifiably focused on improving these elements [5].

In the current study, significant positive correlations were observed between body mass and the results of the dynamometer tests (handgrip and back strength). Detanico et al. also described a strong positive relationship between body mass and maximal strength [19] and that, in the case of athletes, body mass was associated with greater musculature. Consecutively, muscle strength was found to be proportional to the crosssectional area of skeletal muscle [1]. This was also been confirmed in the present study by the significant correlation between handgrip strength and circumference of the upper limbs.

\section{Conclusions}

No pronounced differences were observed between the somatotypes of the jiu-jitsu practitioners and the strength-training university students. This may be may be due to the different sporting level of the participants. However, the better dynamometer results achieved by the strength-training group can be linked to their intensive strength training regime. On the other hand, the more multidimensional aspect of jiu-jitsu training was reflected in achieving better results in the motor tests and undoubtedly connected with the high fitness of these individuals.

\section{References}

1. Zatsiorsky V.M., Kraemer W.J., Science and practice of strength training. Human Kinetics, Champaign 2006.

2. Tan B., Manipulating Resistance Training Program Variables to Optimize Maximum Strength in Men: A Review. J Strength Cond Res, 1999, 13 (3), 289-304.

3. Sterkowicz-Przybycień K., Ambroży T., Sexual dimorphism in anthropometric and fitness measurements of top ju-jitsu contestants. J Combat Sports and Martial Arts, 2013,2 (2), 4, 145-151, doi: 10.5604/20815735.1090660.

4. Costa E.C., Santos C.M., Prestes J., Silva J.B., Knackfuss M.I., Acute effect of static stretching on the strength performance of jiu-jitsu athletes in horizontal bench press. Fit PerfJ, 2009, 8 (3), 212-217, doi:10.3900/fpj.8.3.212.e.

5. Vidal Andreato L., Franzói de Moraes S.M., Lopes de Moraes Gomes T., Del Conti Esteves J.V., Vidal Andreato T., Franchini E., Estimated aerobic power, muscular strength and flexibility in elite Brazilian Jiu-Jitsu athletes. Science \&Sports, 2011,26,329-337, doi:10.1016/j.scispo.2010.12.015.

6. Stefaniak T., Atlas of universal strength exercises. Part 1 [in Polish]. BK, Wrocław 2006.
7. Ibri L., Shala S., Discriminative analysis of morphologic and motoric parameter to judo and karate sportiest boys. Crnogorska Sportska Akademija „Sport Mont”, 2013, 37, 38, 39, 547-553.

8. Sterkowicz-Przybycień K., Technical diversification, body composition and somatotype of both heavy and light Polish ju-jitsukas of high level. Science \& Sports, 2010, 25, 194-200, doi:10.1016/j.scispo.2009.10.005.

9. Lech G., Sterkowicz S., Rukasz W., Significance of body height in martial arts (as exemplified by judo fighters). Hum Mov, 2007, 8 (1), 21-26.

10. Vidal Andreato L., Franzói de Moraes S.M., Del Conti Esteves J.V, de Araujo Pereira R.R., Lopes de Moraes Gomes T.L., Vidal Andreato T. et al., Physiological responses and rate of perceived exertion in Brazilian jiujitsu athletes. Kinesiology, 2012, 44, 2, 173-181.

11. Pieter W., Bercades L.T., Kim G.D., Relative Total Body Fat and Skinfold Patterning in Filipino National Combat Sport Athletes. J Sports Sci Med, 2006, 5, 35-41.

12. Charzewski J., Głaz A., Kuźnicki S., Somatotype characteristics of elite European wrestlers. Biol Sport, 1991, 8 (4), 213-221.

13. Huygens W., Claessens A.L., Thomis M. et al., Body composition estimations by BIA versus anthropometric equations in body builders and other power athletes. J Sports Med Phys Fitness, 2002, 42 (1), 45-55.

14. Imran M., Hussain I., Murtaza S.T. et al., A Comparative Study of Body Builders and Weight Lifters on Somatotypes. Journal of Education and Practice, 2011, 2 (3), 155-160.

15. Sterkowicz-Przybycień K., Sterkowicz S., Żarów R., Somatotype, Body Composition and Proportionality in Polish Top Greco-Roman Wrestlers. J Hum Kinet, 2011, 28, 141-154.

16. Deschenes M.R., Kraemer W.J., Performance and physiologic adaptations to resistance training. Am J Phys Med Rehabil,2002, 81 (11), 3-16, doi: 10.1097/01.PHM.00000 29722.06777.E9.

17. Dias J.A., Wentz M., Külkamp W., Mattos D., Goethel M., Borges Júnior M., Is the handgrip strength performance better in judokas than in non-judokas? Science \& Sports, 2012, 27 (3), 9-14, doi: 10.1016/j.scispo.2011.10.005.

18. Sertić H., Sterkowicz S., Vuleta D., Influence of latent motor abilities on performance in judo. Kinesiology, 2009, 41 (1), 76-87.

19. Detanico D., Budal Arins F., Dal Pupo J., dos Santos S.G., Strength parameters in judo athletes: an approach using hand dominance and weight categories. Hum Mov, 2012, 13 (4), 330-336, doi: 10.2478/v10038-012-0038-x.

Paper received by the Editor: June 17, 2014

Paper accepted for publication: July 25, 2014

\section{Correspondence address}

Jadwiga Pietraszewska

Katedra Motoryczności Sportowca

Akademia Wychowania Fizycznego

al. I.J. Paderewskiego 35, P-2

51-612 Wrocław, Poland

e-mail: jadwiga.pietraszewska@awf.wroc.pl 